\title{
Release of heat shock protein 70 (Hsp70) and the effects of extracellular Hsp70 on matric metalloproteinase-9 expression in human monocytic U937 cells
}

\author{
Kyoung-Jin Lee ${ }^{1,3}$, Yoo Mih Kim ${ }^{1}$, \\ Dae Young Kim ${ }^{1}$, Dooil Jeoung ${ }^{2,3}$, \\ Kyuhyung $\mathrm{Han}^{4}$, Seung-Taek Lee ${ }^{5}$, \\ Yun-Sil Lee ${ }^{6}$, Kyeong Han Park ${ }^{1}$, \\ Jeong Hyun Park', Dae Joong Kim ${ }^{1}$ \\ and Jang-Hee Hahn ${ }^{1,3,7}$
}

\author{
${ }^{1}$ Department of Anatomy and Cell Biology \\ College of Medicine \\ ${ }^{2}$ Department of Biochemistry \\ College of Natural Science \\ ${ }^{3}$ Vascular System Research Center \\ Kangwon National University \\ Chuncheon 200-701, Korea \\ ${ }^{4}$ Department of Biomedical Science \\ and Institute of Bioscience and Biotechnology \\ College of Natural Sciences, Hallym University \\ Chuncheon 200-702, Korea \\ ${ }^{5}$ Department of Biochemistry \\ College of Sciences, Yonsei University \\ Seoul 120-749, Korea \\ ${ }^{6}$ Laboratory of Radiation Effect \\ Division of Radiation Biology \\ Korea Institute of Radiological and Medical Sciences \\ Seoul 139-706, Korea \\ ${ }^{7}$ Corresponding author: Tel, 82-33-250-8811; \\ Fax, 82-33-250-8811; E-mail, jhahn@kangwon.ac.kr
}

Accepted 1 June 2006

Abbreviations: AP-1, activating protein-1; HCS, Hsp70-overexpressing cells culture supernatants; Hsp, heat shock protein; HUVEC, human umbilical vascular endothelial cells; MCS, mock transfected cells culture supernatants; MMP-9, matrix metalloproteinase-9; $\mathrm{NF}-\mathrm{kB}$, nuclear factor kappa B; SFM, serum-free medium; TLR, Toll-like receptor

\begin{abstract}
Heat shock protein $70(\mathrm{Hsp} 70)$ release and its effects on pro-inflammatory cytokine production have been controversial. In this study, we investigated whether Hsp70 could be released from monocytes and activates matrix metalloproteinase-9 (MMP-9) gene expression. Hsp70 overexpression in human mono-
\end{abstract}

cytic cell line U937 was found to increase PMAinduced MMP-9 expression and enhance cell motility. Hsp70 cDNA transfectants released Hsp70 protein into culture supernatants, and a part of released Hsp70 subsequently was bound to the surface of U937 cells. Addition of culture medium containing the extracelluar Hsp70 led to an increase not only in proMMP-9 secretion, but also the invasiveness of U937 cells through Matrigel or human umbilical vascular endothelial cells (HUVEC) in vitro. Im munodepletion of Hsp70 abolished its effect on MMP-9 expression. The released Hsp70 activated nuclear factor kappa B (NF-KB) and activating protein-1 (AP-1), which led to the activation of MMP-9 transcription. Taken together, these results suggest that extracellular Hsp70 induces the expression of MMP-9 gene through activation of NF-KB and AP-1.

Keywords: AP-1; gelatinase B; HSP70 heat-shock proteins; monocytes; NF-kB; transcription factor AP-1

\section{Introduction}

Most organisms express constitutive and stressinduced forms of Hsp70, which are involved in protein folding, translocation, oligomer dissociation, and prevention of protein aggregation. Since Hsp70 lacks any secretory signal sequence, it has been considered as an intracellular molecule (Gething and Sambrook, 1992; Hartl and Hayer-Hartl, 2002). However, it has been suggested that Hsp70 is released extracellularly under normal cell culture conditions (Hightower et al., 1989; Broquet et al., 2003; HunterLavis et al., 2004), and is present in circulation of normal individuals, and its circulating level is increased after open heart surgery or in patients with cardiovascular diseases including atherosclerosis (Chan et al., 1999; Dybdahl et al., 2002). Furthermore, plasma concentrations of Hsp70 were shown to be associated significantly with postoperative infection (Kimura et al., 2004). These results suggest that $\mathrm{Hsp} 70$ can be released into extracellular spaces and may be involved in postoperative inflammatory responses and in the pathogenesis of postoperative organ dysfunction. In fact, it has been shown to interact with the CD14 and Toll-like receptor 2 (TLR2) and TLR4 on antigen-presenting cells such 
as macrophages and dendritic cells, and directly induce expression of cytokines such as interleukin-1 $\alpha$ $(\mathrm{IL}-1 \alpha)$, IL-1 $\beta$, IL-6, tumor necrosis factor- $\alpha$ (TNF- $\alpha)$, and granulocyte-macrophage colony-stimulating factor (GM-CSF) in macrophage cultures (Asea et al., 2000). Thus, the induction of pro-inflammatory cytokines by extracellular Hsp70 may stimulate the innate immune response to promote chronic inflammation. However, some results suggest that the reported cytokine function of $\mathrm{Hsp} 70$ may have resulted from contamination by lipopolyscharride (LPS) (Bausinger et al., 2002; Gao and Tsan, 2003a, b, c; Tsan and Gao, 2004a, b c; Wang et al., 2005). For example, it was reported that LPS-free recombinant human $\mathrm{Hsp} 70$ could not induce the activation of dendritic cells (Bausinger et al., 2002). The ability of commercially available rhHsp70 to induce TNF- $\alpha$ production was also shown to be entirely due to contamination by LPS as well as LPS-associated molecules (Gao and Tsan, 2003a, b). Thus, the question of whether the released Hsp70 has any cytokine effect still remains elusive.

MMP-9 is a $92-\mathrm{kDa}$ type IV gelatinase that is produced by human monocytes/macrophages (Nagase et al., 1992). It cleaves basement membrane collagen IV and V and gelatin, fibronectin, and elastin, (Tryggvason et al., 1992) and plays a crucial role in monocyte extravasation, which is a primary event in inflammation (Watanabe et al., 1993). Its expression is regulated by cytokines, chemokines, and cellular interactions through adhesion molecules (Opdenakker et al., 2001; Hong et al., 2005). In this study, we investigated whether extracellular Hsp70 could be released from living Hsp70 transfectants and induce MMP-9 gene expression. This study shows that Hsp70 is released actively from monocytic cells, and enhances MMP-9 expression and activity through activation of NF-kB and AP-1.

\section{Materials and Methods}

\section{Reagents}

Culture reagents were purchased from Invitrogen (Carlsbad, CA). Anti-human Hsp70 mAb was purchased from Stressgen Bioreagents (Victoria, BC, Canada). Horseradish-conjugated goat anti-mouse IgG was from Chemicon (Temecula, CA). FITCconjugated anti-mouse $\lg G$ antibody was from Becton Dickinson (San Jose, CA). Anti-human $\alpha$ - and $\beta$ actin $\mathrm{mAb}$ and PMA were from Sigma-Aldrich Co. (St. Louis, MO). Nitrocellulose membranes and the antibody detection kit (ECL plus) were obtained from Amersham Biosciences (Piscataway, NJ). [ $\left.\alpha-\mathrm{P}^{32}\right]$ dCTP $(3,000 \mathrm{Ci} / \mathrm{mmol})$ was supplied by Perkin Elmer (Boston, MA). TRIzol reagent was from Life Tech- nologies (Rockville, MD). Dual-luciferase reporter assay system was from Promega (Madison, WI).

\section{DNA constructs and transfection}

The full-length cDNA coding for inducible Hsp70 was subcloned into the HindIII and Xbal sites of a stable expression vector, pcDNA3.1 (Invitrogen Corp., Carlsbad, CA). All sequences of the construct were confirmed by DNA sequencing. DNA transfection to U937 cells was performed using an electroporator (Invitrogen Corp.). pcDNA3.1 vector only was also transfected as a control. Stable transfectants were selected in RPMI1640 medium, containing 10\%

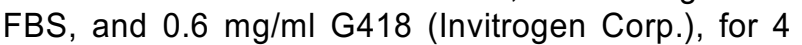
weeks. Resistant clones were selected, and their expression levels of Hsp70 were then examined by Western blot analysis.

\section{Cell culture}

Human monocytic cells (U937) were obtained from American Type Culture Collection (ATCC), and were cultured in RPMI1640 medium supplemented with $10 \%$ fetal bovine serum (FBS), $100 \mathrm{U} / \mathrm{ml}$ penicillin, and $100 \mu \mathrm{g} / \mathrm{ml}$ streptomycin (all from Invitrogen Corp.). For cultures of the Hsp70- transfected U937 cells, G418 was added to the complete RPMI medium at a concentration of $0.6 \mathrm{mg} / \mathrm{ml}$. Cell cultures were maintained and incubated in $5 \% \mathrm{CO}_{2}$ at $37^{\circ} \mathrm{C}$.

\section{Flow cytometric analysis}

At an appropriate time point, U937 cells $\left(5 \times 10^{5}\right.$ cells) were centrifuged at $3,000 \mathrm{rpm}$, and the pellets were washed with serum free RPMI1640, resuspended in $200 \mu \mathrm{l}$ of serum-free medium (SFM) including $1 \mu \mathrm{g}$ of anti-human $\mathrm{Hsp} 70$ monoclonal antibody, and incubated for $30 \mathrm{~min}$ at $4^{\circ} \mathrm{C}$. Unbound $\mathrm{mAb}$ was removed by washing three times with SFM. The cells were resuspended in $200 \mu$ of SFM, including $1 \mu \mathrm{g}$ of FITC-conjugated anti-mouse IgG antibody, and incubated for $30 \mathrm{~min}$ on ice. The cells were finally resuspended in $400 \mu$ of cold $1 \times$ PBS containing $1 \%$ formalin. Fluorescence intensity was measured with a FACS Scan Flow Cytometer (Becton Dickinson, San Jose, CA).

\section{Gelatin zymogram assay}

The amount of proMMP-9 secreted was assayed by geleatin zymography as described previously (Lee et al., 2004). 


\section{Western blot analysis}

Western blot analysis used for detecting Hsp70 protein expression was carried out as described previously (Lee et al., 2004).

\section{Northern blot analysis}

Expression of MMP-9 mRNA was determined by Northern blot analysis as previously described (Lee et al., 2004).

\section{Immunodepletion}

Concentrated culture supernatants were incubated with anti-human Hsp70 monoclonal antibody (1:100 dilution) (StressGen Bioreagents) or an equal amount of mouse $\lg G$ for $22 \mathrm{~h}$ and then incubated with protein A-agarose (Life Technologies) for $2 \mathrm{~h}$ on a roller system at $4^{\circ} \mathrm{C}$. The culture supernatants and control medium were used to stimulate U937 cells in 35-mm dishes, and MMP-9 activity was analyzed by zymography.

\section{Determination of cell viability}

Cell viability was assessed by the dye exclusion test. Cells were incubated in SFM for $24 \mathrm{~h}$ at $37^{\circ} \mathrm{C}$. For quantitative analysis of cell viability, cells were collected at the indicated time. After washing, $0.1 \mathrm{ml}$ of the culture sample was stained with $0.1 \mathrm{ml}$ of $0.4 \%$ trypan blue, and the number of living and dead cells was then counted using a hemocytometer.

\section{Transmigration assay}

Polycarbonate filters (8- $\mu \mathrm{m}$ pore size; Costar) were coated with Matrigel and placed in a modified Boyden chamber, filled with $600 \mu$ of NIH3T3 cell cultured-DMEM conditioned medium, $0.005 \%$ vita$\min \mathrm{C}$, and $0.1 \% \mathrm{BSA}$ as a source of chemoattractants in the lower compartment. Then, $100 \mu \mathrm{l}$ of U937 cell suspension $\left(1 \times 10^{6}\right.$ cells $/ 100 \mu \mathrm{I}$ SFM) were placed in the upper compartment of the chamber. The plates were incubated at $37^{\circ} \mathrm{C}$ in $5 \% \mathrm{CO}_{2}$ in air saturated with $\mathrm{H}_{2} \mathrm{O}$ for $24 \mathrm{~h}, 48 \mathrm{~h}$, and $72 \mathrm{~h}$, and the cells on the lower surface of the filter were then stained with trypan-blue and counted. Each assay was carried out in triplicate. Invasion rate was determined as a percentage of control.

\section{Endothelial leukocyte transmigration assay}

HUVEC were seeded onto Matrigel-coated Transwell polycarbonate filter inserts (24-well format, pore size $8 \mu \mathrm{m}$ ) in growth medium and grown to confluence. Monolayer integrity was assessed in parallel inserts by crystal violet staining followed by light microscopy. Forty eight hours after reaching confluence, endothelial monolayers were stimulated with growth medium containing chemoattractants used in cell invasion assay. U937 cells were suspended in RPMI 1640 medium containing 10\% (v/v) FBS and $1 \%(\mathrm{w} / \mathrm{v})$ of glutamine, and $1 \times 10^{6}$ cells were added on top of the endothelial monolayers. U937 cells were allowed to migrate for $48 \mathrm{~h}$ at $37^{\circ} \mathrm{C}$ in $5 \% \mathrm{CO}_{2}$, and transmigrated cells in the lower chamber were counted under a light microscope. Assays were carried out in triplicates.

\section{Confocal microscopy}

To determine the binding of secreted Hsp70 to the surface of U937 cells, cells were harvested with 200 $\mu \mathrm{l}$ of SFM including $1 \mu \mathrm{g}$ of anti-human Hsp70 monoclonal antibody in the presence or absence of secreted Hsp70 in fresh Eppendorf-tube and incubated for $2 \mathrm{~h}$ at room temperature. To eliminate unbound $\mathrm{mAbs}$, they were washed with $1 \mathrm{ml}$ of SFM and resuspended in $200 \mu \mathrm{l}$ of SFM, containing $1 \mu \mathrm{g}$ of FITC-conjugated anti-mouse IgG antibody and incubated for $2 \mathrm{~h}$ at room temperature. They were finally resuspended in $400 \mu$ of cold $1 \times$ PBS containing $1 \%$ formalin, and analyzed under a confocal microscope (Leica TCS SP; Leica, Deerfield, IL).

\section{Transfection of promoter/luciferase constructs and luciferase assay}

The structure of pGL3-M9Pwt, pGL3-M9Pmt-NF-кB, pGL3-M9Pmt-AP-1, and pRL-SV40 $\triangle$ enh that expresses Renilla luciferase by an enhancerless SV40 promoter were previously described (Hah and Lee, 2003). pNF $\kappa B-T A-L u c$ and pAP1-TA-Luc were obtained from Clontech (Mountain View, CA) and their structures were described in the manufacturer's manual. U937 cells were transiently transfected with pGL3-M9Pwt, pGL3-M9Pmt-NF-kB, pGL3-M9PmtAP-1, pNF $\kappa B-T A-L u c$, or pAP1-TA-Luc, using electroporation. pRL-SV40 $\triangle E$ nh was also transfected to normalize the luciferase activity, which was measured by using the dual-luciferase reporter assay system (Promega).

\section{Statistical analysis}

The data are expressed as the average of the mean values obtained \pm SD. Statistical significance was determined by the Student's $t$ test with the statistical software GraphPad Prism (version 4.0). All experiments were conducted three times or more for obtaining reproducible results. The representative data are shown in the figures. 
A
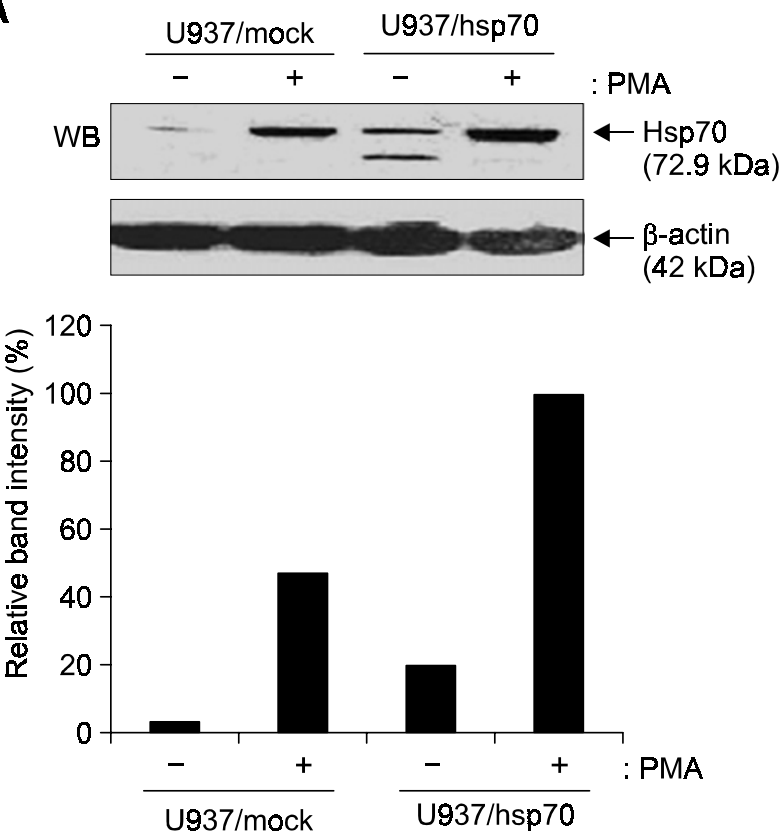

B

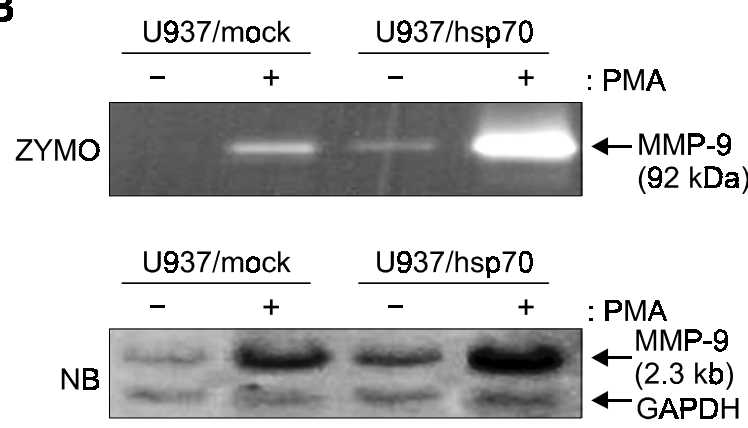

$(1.3 \mathrm{~kb})$
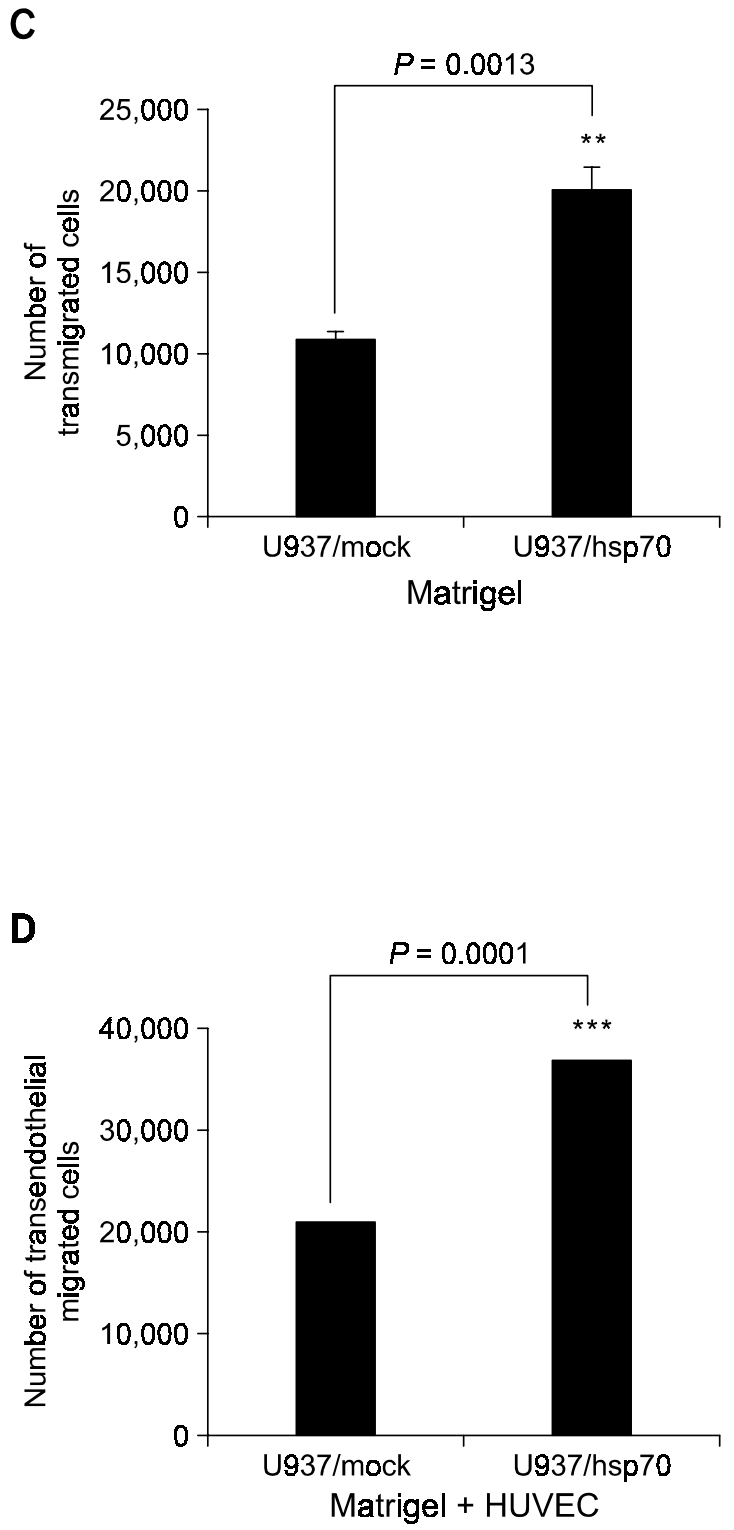

Figure 1. MMP-9 expression and secretion are upregulated in the Hsp70 overexpressing clone. (A) Expression level of Hsp70 in Hsp70 cDNA transfected clone. Mock-vector transfected U937 or Hsp70 cDNA transfected U937 cells were incubated in serum-free medium in the absence or presence of PMA $(3 \mathrm{nM})$. After $24 \mathrm{~h}$, the cells were lysed with 1\% NP-40 lysis buffer. Expression levels of Hsp70 protein in mock-vector transfected U937 or Hsp70 transfected U937 clone were analyzed by Western blot analysis. Results were replicated in three independent experiments. A relative expression level of $\mathrm{Hsp} 70$ is shown as a relative intensity of bands by measuring with a densitometer. (B) U937 mock transfectants and Hsp70 cDNA transfectants were incubated for $24 \mathrm{~h}$ in the absence or presence of PMA $(3 \mathrm{nM})$. Samples of conditioned medium were collected, and then analyzed for the proMMP-9 secretion by gelatin zymographic analysis (upper panel), or analyzed for MMP-9 mRNA expression by Northern blot analysis (lower panel). GAPDH bands were detected as loading controls. (C) Effect of Hsp70 on transmigration ability of U937 cells. Polycarbonate filters coated with Matrigel were placed in a modified Boyden chamber. Boyden chambers were filled with conditioned medium of NIH3T3 cells. Then, U937 cells or Hsp70 overexpressing U937 $\left(1 \times 10^{6}\right.$ cells $)$ cells were placed in the upper compartment of the chamber. After $24 \mathrm{~h}$, cells that had migrated to the lower wells were stained with trypan-blue and counted under the light microscope. Bar graphs were calculated from no less than three independent experiments each in duplicates. A significant difference from control is shown by asterisks as follows: ${ }^{* *} P$ $<0.01 ;{ }^{* * *} P<0.001$. Lines indicate additional statistical comparisons. (D) HUVECs were grown on Transwell cell culture inserts to confluence, and then transmigration assay was performed as described in (C). 


\section{Results}

\section{Hsp70 overexpression enhances MMP-9 activity}

In order to confirm the previously reported cytokine function of $\mathrm{Hsp} 70$ under the condition of excluding a possibility of bacterial lipopolysacharide contamination (Bausinger et al., 2002; Gao and Tsan, 2003a, b, 2004; Tsan and Gao, 2004a, b), Hsp70 was overexpressed in the human monocytic U937 cells, and its effect on MMP-9 expression was then
A
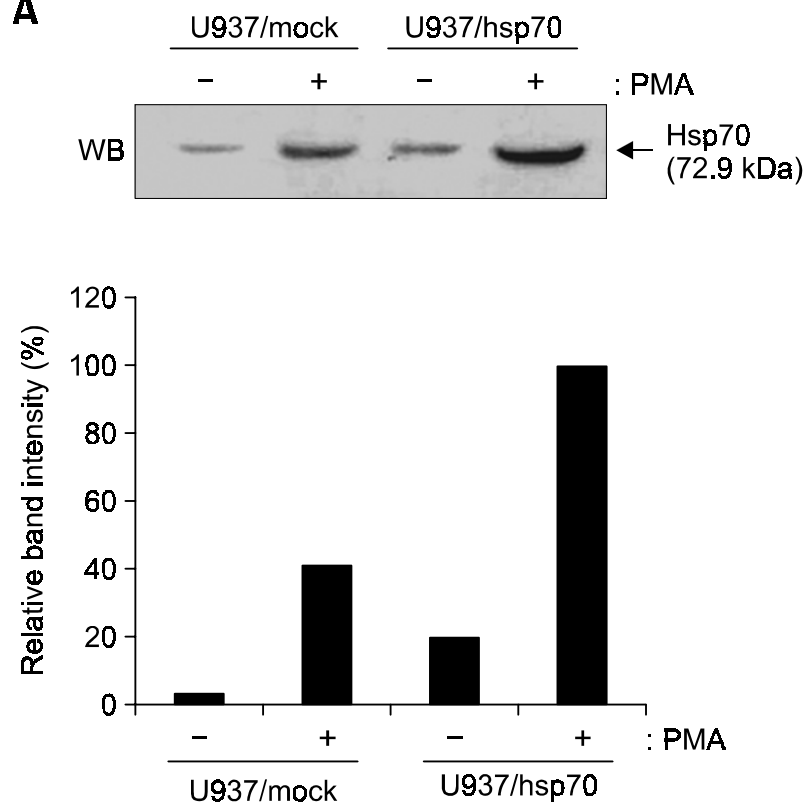

B

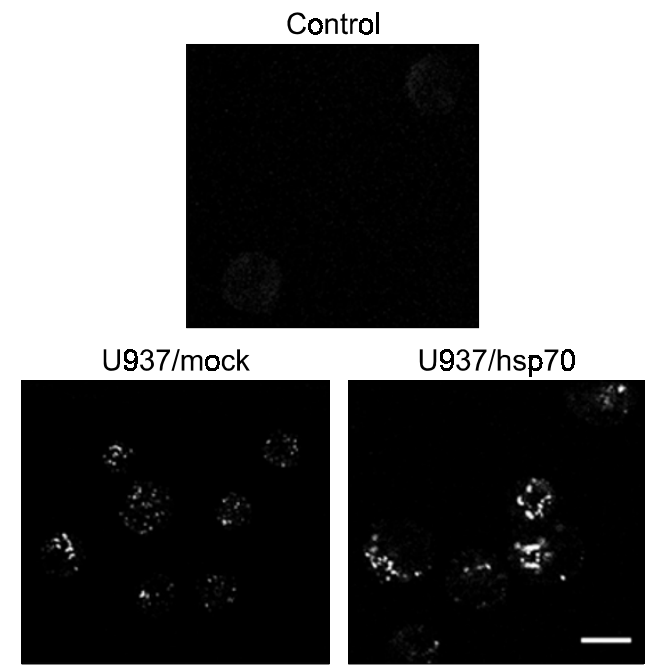

C
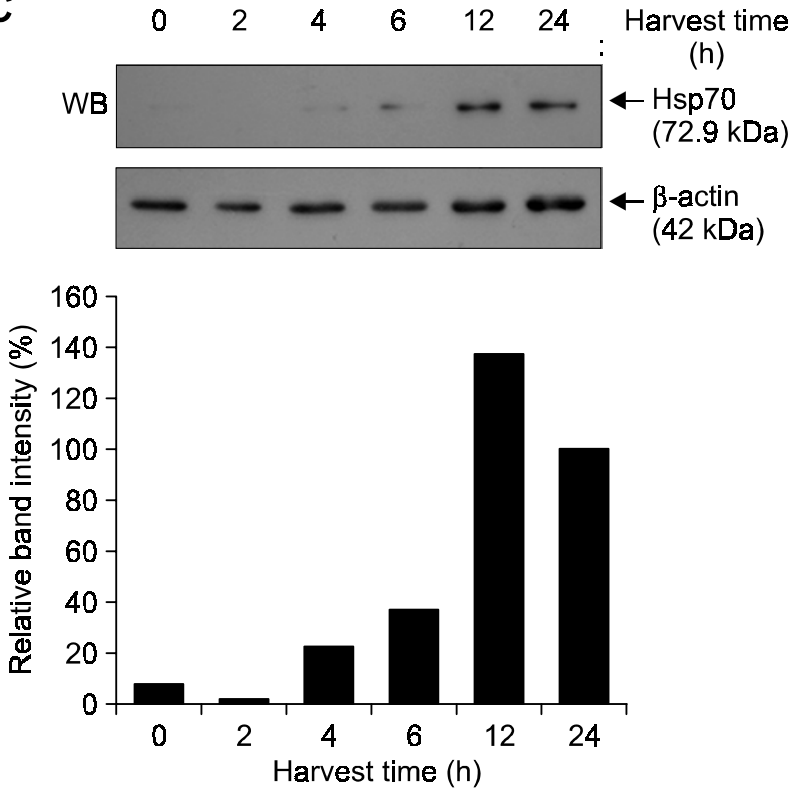

D

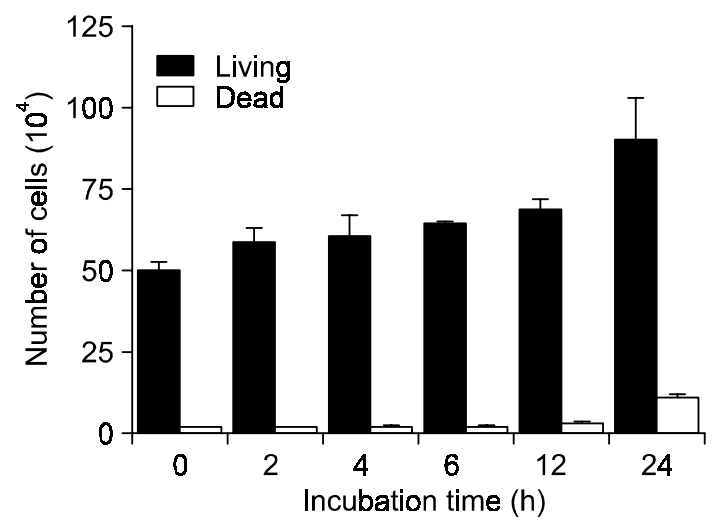

Figure 2. Hsp70 is secreted from the U937 cells. (A) U937 mock transfectants and Hsp70 cDNA transfectants were incubated for $24 \mathrm{~h}$ in the absence or presence of PMA ( $3 \mathrm{nM})$. After $24 \mathrm{~h}$, culture supernatants were collected, and analyzed for Hsp70 expression by Western blot analysis. The graph represents relative expression level of Hsp70, shown as relative band intensity by measuring with a densitometer. (B) The secreted Hsp70 binds onto the surface of U937 cells. To confirm the binding of secreted-Hsp70 to the cell surface, U937 mock transfectants and Hsp70 cDNA transfectants were incubated for $24 \mathrm{~h}$ in the presence of PMA $(3 \mathrm{nM})$. After $24 \mathrm{~h}$, culture supernatants were collected, and then added to the freshly cultured U937 cells, respectively. After $1 \mathrm{~h}$, the cells were stained with anti-Hsp70 mAb and FITC-conjugated anti-mouse IgG, and analyzed by confocal microscopy. Scale bar, $200 \mu \mathrm{m}$. (C) Kinetics of Hsp70 secretion from Hsp70 cDNA transfectants. Hsp70 cDNA transfectants were incubated for $24 \mathrm{~h}$ in the absence of PMA. The equal amounts of culture supernatants were collected at the indicated time, and then analyzed for Hsp70 and actin expression by Western blot analysis. The graph represents relative expression levels of $\mathrm{Hsp} 70$ and actin, shown as a relative intensity of bands by measuring with a densitometer. (D) Cell viability was assessed by the dye exclusion test as depicted in Materials and Methods. 
investigated. As shown in Figure 1A, Hsp70 was detected in both Hsp70- and mock-transfected cells. However, increased level of Hsp70 protein expression was observed only in the Hsp70-transfected cells. There was about a five-fold increase in the Hsp70 expression level after stimulating the Hsp70 transfected cells with PMA (3 nM). Hsp70 and mock transfectants were cultured in the presence or absence of PMA in serum free medium for $24 \mathrm{~h}$, and then supernatants were collected to measure MMP. 9 expression by gelatin zymography (Figure 1B upper panel). Quiescent mock transfectants secreted proMMP-9 at barely detectable levels. In contrast, the overexpression of Hsp70 induced detectable levels of MMP-9 expression. Stimulation of mock and Hsp70 transfectants with PMA markedly augmented proMMP-9 expression levels in the supernatants. We next investigated by Northern blot analysis whether the stimulatory effect of Hsp70 on proMMP-9 secretion resulted from increased MMP-9 mRNA expression. As shown in Figure 1B lower panel, the result indicates that U937 cells expressed the $2.3 \mathrm{~kb}$ mRNA species for MMP-9, and Hsp70 transfectants induced more MMP-9 mRNA expression than mock transfectants. These results demonstrate that overexpression of $\mathrm{Hsp} 70$ increases MMP-9 mRNA expression in monocytes/macrophages.

MMP-9 has been known to play a crucial role in leukocyte migration from the circulation to inflamed tissues (Hah and Lee, 2003). Having found the stimulatory effect of overexpression of Hsp70 on PMA-induced MMP-9 mRNA expression, we were interested to determine whether Hsp70-induced proMMP-9 expression could increase the ability of monocytes to infiltrate through extracellular matrix. Therefore, transmigration ability of Hsp70-transfected U937 cells was compared with that of mocktransfectants by a Matrigel invasion assay. The number of transmigrated Hsp70-transfected U937 cells was an about two-fold more than that of mocktransfectants (Figure 1C). In addition, we examined whether Hsp70 had an effect on leukocyte transendothelial migration. HUVECs were grown on Transwell cell culture inserts to confluence and subjected to a transmigration assay by adding a defined number of mock transfectants or Hsp70-transfected U937 cells to the upper wells. As shown in Figure 1D, the overexpression of Hsp70 led to a marked increase of U937 transendothelial migration (migrated cell number; 35,000 ), as compared with control $(20,000)$. This finding suggests that $\mathrm{Hsp} 70$ may play a role in the human microvasculature as a potential proinflammatory mediator.

\section{Hsp70 is secreted from the cells to culture super- natants, and binds to the cell surface}

There are a number of reports on the secretion of Hsp70 independent of necrotic cell death (Hightower et al., 1989; Broquet et al., 2003; Esparza et al., 2004; Hunter-Lavis et al., 2004; Adewoye et al., 2005; Dybdahl et al., 2005; Svensson et al., 2005). To explore whether Hsp70 could be released from Hsp70 transfectants to the culture medium, Hsp70 and mock transfectants were cultured in the absence or presence of PMA, and the amount of Hsp70 released in the culture medium was then measured by Western blot analysis. As shown in Figure 2A, there was about two-fold more Hsp70 in the culture medium of Hsp70-transfected cells than that of mock-transfectants. Next, we investigated whether the released Hsp70 was bound to the surface membrane of U937 cells. The result showed that the released $\mathrm{Hsp} 70$ was bound to the surface membranes of approximately $20 \%$ of the cells (Figure 2B). Consistent with Western blot analysis, the staining intensity was higher in the Hsp70 transfectants than in mock transfectants. Mock transfectants treated with only FITC-conjugated antimouse IgG antibody showed barely detectable staining pattern. These results were confirmed by flow cytometric analysis by using an indirect immunofluorescence technique with anti-Hsp70 mAb and FITC-conjugated anti-mouse IgG antibody. Mean fluorescence intensity was 48.80 arbitrary units, compared with mock-transfected cells of 13.72 arbitrary units. To determine whether extracellular Hsp70 was released from living Hsp70 transfectants, we measured the protein abundance of Hsp70 released into medium and compared it with that of an intracellular protein, $\beta$-actin (Figure 2C). Hsp70 transfectants were cultured in serum-free medium in the absence of PMA for $24 \mathrm{~h}$, and then culture supernatants were collected at the indicated time. Culture media at $0 \mathrm{~h}$ and $2 \mathrm{~h}$ showed very low levels of Hsp70, but relatively high levels of $\beta$-actin (lane 2 and 3 ). From 4 h-culture medium, however, the secretion of Hsp70 started to increase. After culture for 12-24 $\mathrm{h}$, there was an about 10-14 fold increase in Hsp70 present in serum-free medium (Figure 2C, lane 6$)$, but an about two-fold increase in $\beta$-actin. To verify that the Hsp70 release was not due to cell death, cell viability was determined every $2 \mathrm{~h}$ for 24 $\mathrm{h}$ by trypan blue staining. There was no significant decrease of cell viability when cells were cultured for $24 \mathrm{~h}$ (Figure 2D). In addition, there was no noticeable change of morphology in Hsp70 transfectatns for $24 \mathrm{~h}$ (data not shown). Taken together, these results suggest that regulated secretion of $\mathrm{Hsp} 70$ occurred for $24 \mathrm{~h}$ of culture. 
A
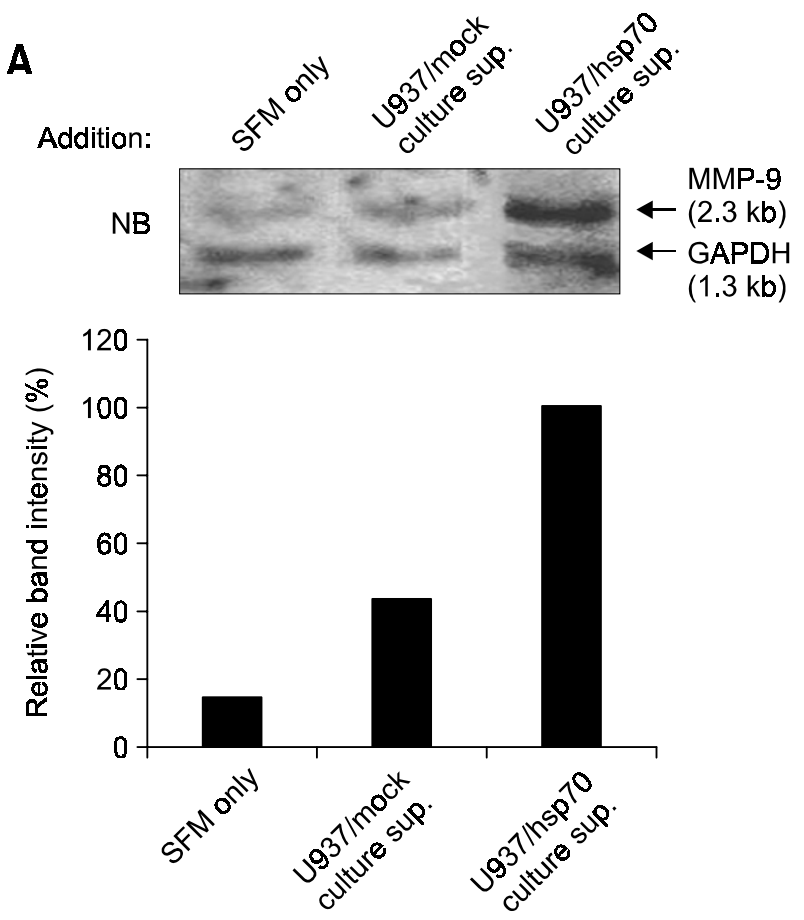

B

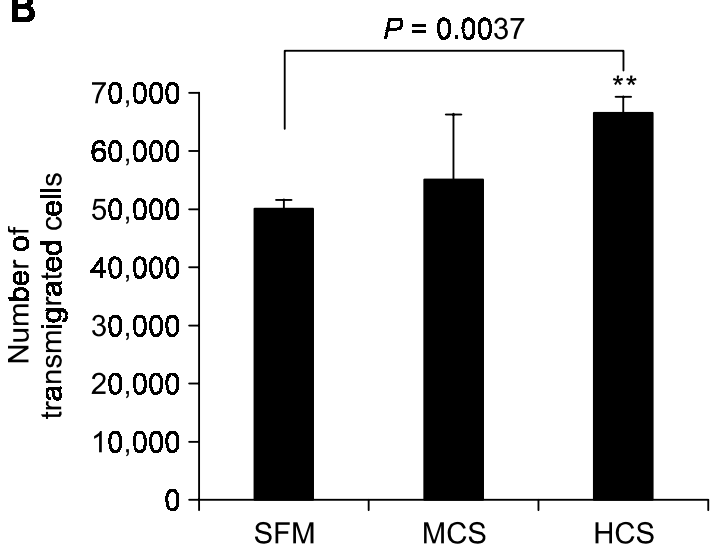

C
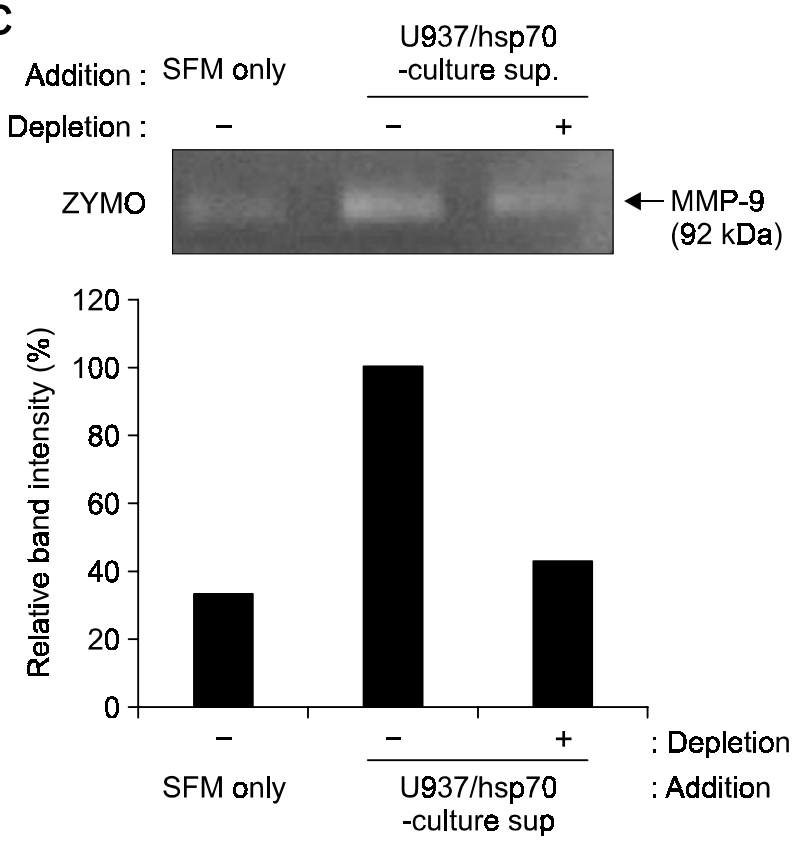

D

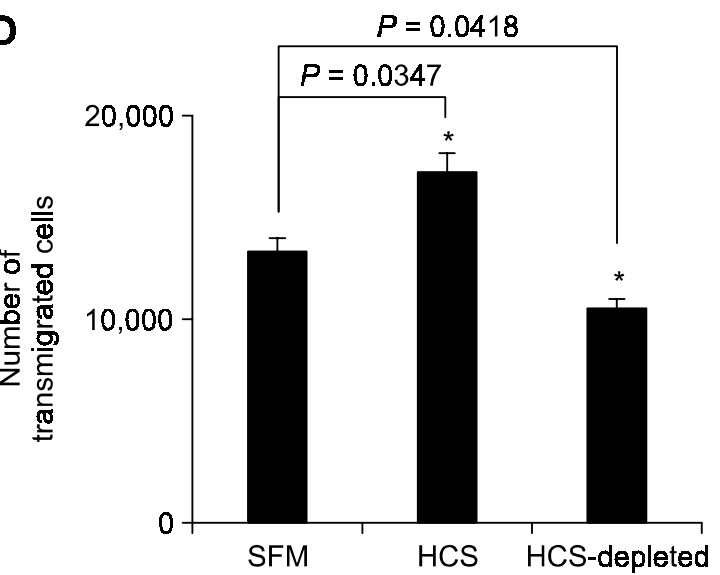

Figure 3. Effects of secreted Hsp70 on MMP-9 expression, secretion, and migration ability of U937 cells. (A) Hsp70-overexpressing U937 cells and mock transfectants were cultured in the absence of PMA. After $24 \mathrm{~h}$, culture supernatants were collected, and added to U937 cell cultures. After another $24 \mathrm{~h}$ incubation, the cultured cells were harvested, and total RNA was isolated from them. MMP-9 mRNA expression was analyzed by Northern blotting analysis. (B) Hsp70-overexpressing U937 cells and mock transfectants were incubated for $24 \mathrm{~h}$ in serum-free medium. After that, culture supernatants was collected, and mixed with serum-free medium in the ratio of 1:1 (v/v). Then, U937 cells suspended in mixed culture medium were placed in the upper compartment coated with Matrigel of a modified Boyden chamber. The lower compartment of Boyden chambers was filled with conditioned medium of NIH3T3 cells. The cells migrated to the lower chamber were counted every $24 \mathrm{~h}$ for $72 \mathrm{~h}$. Each assay was carried out in triplicates. Asterisks show a significant difference from control as follows: ${ }^{* *} P<0.01$. Lines indicate additional statistical comparisons. SFM, serum free media; MCS, mock transfected cells culture supernatant; HCS, Hsp70-overexpressing cells culture supernatant. (C) Effect of depletion of secreted Hsp70 on the proMMP-9 secretion. Hsp70-overexpressing U937 cells were incubated for $24 \mathrm{~h}$ in serum-free medium. After that, culture supernatants were collected and divided into two groups. One group was incubated overnight with mouse $\mathrm{lg}$ and protein A-conjugated beads. The other group was incubated overnight with anti-Hsp70 polyclonal antibody and protein A-conjugated beads. After centrifugation, culture supernatants were added to U937 cells for $24 \mathrm{~h}$. Culture medium was taken, and analyzed for MMP-9 activity by the zymographic analysis. The bottom panel depicts densitometric analysis of upper panel result. (D) Hsp70-overexpressing U937 cells were incubated for $24 \mathrm{~h}$ in serum-free medium, and then culture supernatants were collected and divided into two groups. Immunodepletion of $\mathrm{Hsp} 70$ protein was performed as described in (C). Then, transmigration assay was carried out as described in (B). Asterisks show a significant difference from control as follows: ${ }^{*} P<0.05$. Additional statistical comparisons are indicated by lines. 


\section{The secreted Hsp70 increases MMP-9 expression and migrating ability of cells}

Since Hsp70 could be released from cells as described above, we next examined whether the released Hsp70 could induce MMP-9 mRNA expression. After U937 cells were incubated in the culture supernatants containing the released Hsp70, MMP-9 mRNA expression levels were determined by Northern blot analysis. Figure $3 \mathrm{~A}$ shows that culture supernatants from Hsp70 transfectants induced the MMP-9 mRNA expression about a 2.5-fold more than those from mock transfectants. Addition of serum- free medium alone had little effect on MMP-9 mRNA expression. These findings indicate that extracellular Hsp70 activates MMP-9 gene expression. To further evaluate the relationship between the released Hsp70 and MMP-9 gene expression in U937 monocytes, we treated U937 cells for $24 \mathrm{~h}$ with serum-free medium plus culture supernatants

A
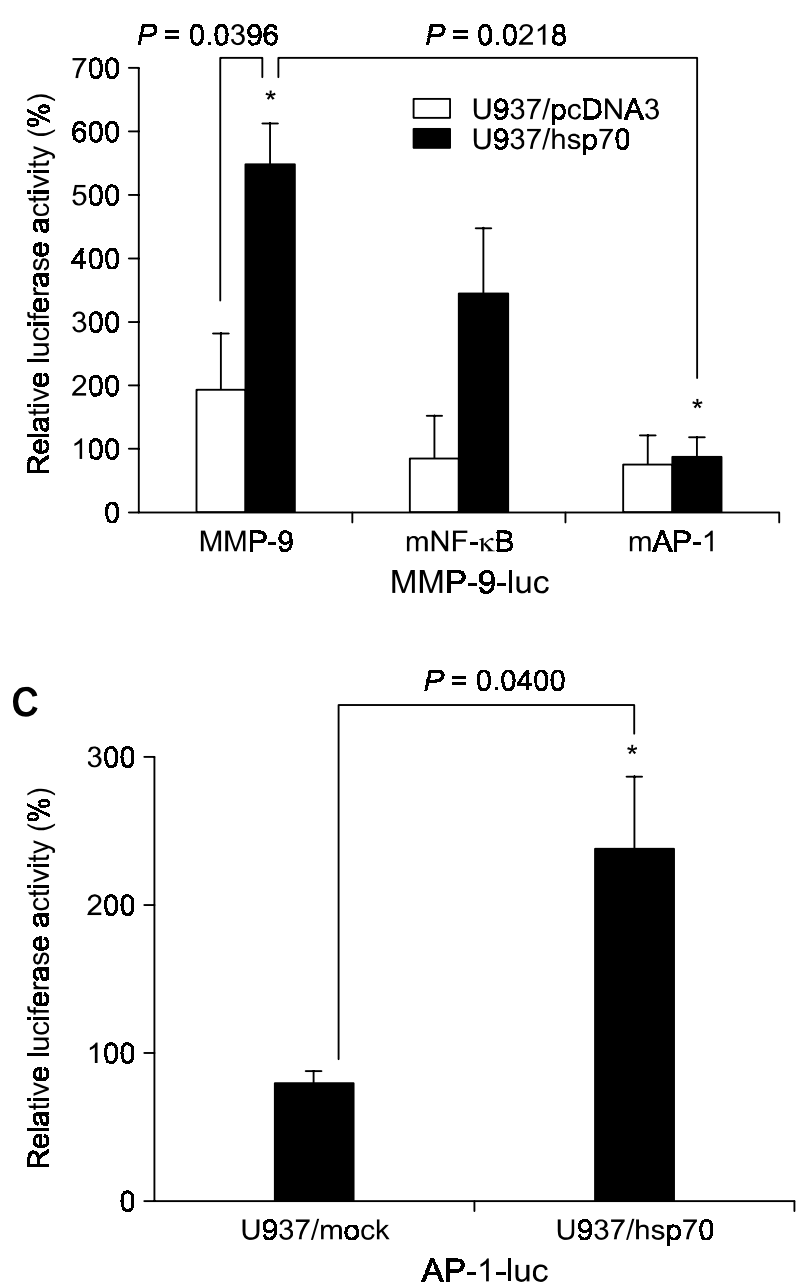

taken from mock or Hsp70 transfectants, and then determined the effect of culture supernatants on invasiveness using the modified Boyden chamber assay. The invasion rate was the highest in U937 cells incubated with culture supernatants from Hsp70 overexpressing cells, reflecting the amount of Hsp70 released (Figure 3B). To determine the extent to which secreted Hsp70 increases MMP-9 expression and cell invasion, Hsp70 in culture medium was immunodepleted with anti-Hsp70 polyclonal antibody or rabbit IgG. As shown in Figure $3 \mathrm{C}$, immunodepletion with anti-Hsp70 polyclonal antibody resulted in a more than $60 \%$ decrease in MMP-9 secretion, as compared with contol. Figure $3 D$ shows that depletion of Hsp70 led to a marked decrease in invasiveness (migrated cell number, 10,000), as compared with control $(17,000)$. These results indicate that the secreted Hsp70 can induce MMP-9 mRNA expression and proMMP-9 secretion, consequently increasing invasive ability of the cells.

B

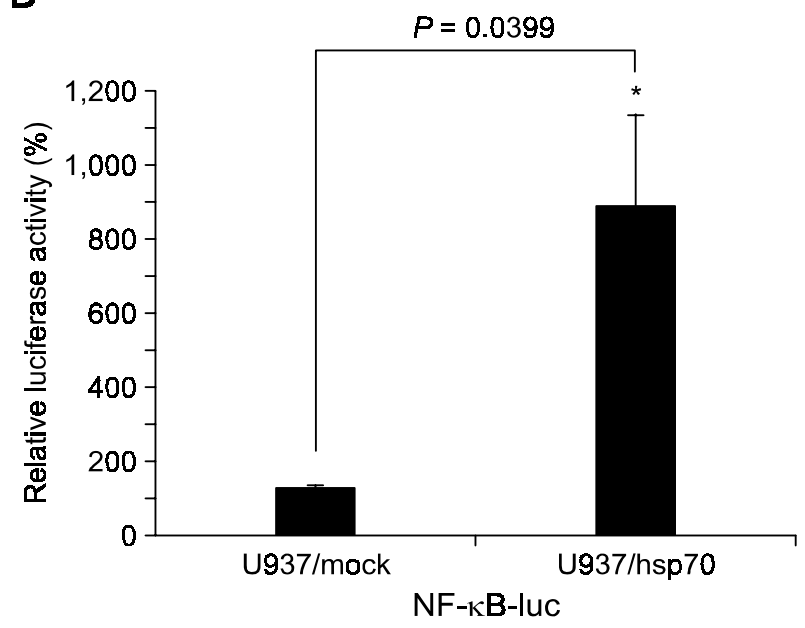

Figure 4. Hsp70 increases the transcription of MMP-9 gene by activating $A P-1$ and NF-kB. U937 cells were transiently transfected with pRL-SV40 $\triangle$ enh and pGL3-M9Pwt, pGL3-NF-kBmut, or pGL3-AP1 mut (A), pGL3-NF-kBwt (B), or pGL3-AP-1wt (C). pRL-SV40 $\triangle$ Enh was also transfected to normalize the luciferase activity. After transfection, cells were incubated for $24 \mathrm{~h}$ at $37^{\circ} \mathrm{C}$ in a $\mathrm{CO}_{2}$ incubator. The levels of promoter activity were determined by luciferase assay as described in Materials and Methods. Relative luciferase activity was shown as the mean \pm S.D. relative to the activity of untreated controls that is designated as $100 \%$. A significant difference from the control is shown by asterisks as follows: ${ }^{*} P<0.05$. Additional statistical comparisons are indicated by lines 


\section{The released Hsp70 activates NF-kB and AP-1}

To investigate whether extracellular Hsp70 activates MMP-9 expression at the transcriptional level, the effect of Hsp70 on MMP-9 gene expression was assessed using the luciferase reporter gene assay. Hsp70 overexpression induced about a three-fold increase in the MMP-9 promoter-mediated luciferase activity in U937 cells transiently transfected with the MMP-9 promoter construct (Figure 4A). These results are consistent with Northern blot analysis described above. In addition, a mutation of the NF-kB binding site (pGL3-M9Pmt-NF- $\kappa$ B) decreased the activation of the MMP-9 promoter by Hsp70 and mutations of the two AP-1 binding sites (pGL3M9Pmt-AP-1) drastically decreased the induction (Figure 4A). These results show that both $N F-k B$ and AP-1 binding sites in the MMP-9 promoter are necessary for Hsp70-induced MMP-9 activation. Next, using NF-kB and AP-1 promoter luciferase constructs, we determined whether Hsp70 activated $\mathrm{NF}-\kappa \mathrm{B}$ and AP-1 activities, which have been shown to play a key role in regulating MMP-9 gene expression (Sato et al., 1993; Hah and Lee, 2003; Lee et al., 2004). NF-KB activity was approximately a seven-fold higher in the Hsp70 transfectants than in control (Figure 4B). This result is consistent with the previous result showing that exogenous Hsp70 activates the transcription activity of NF- $\mathrm{KB}$ (Asea et al., 2002). Similarly, AP-1 activity was nearly a three-fold higher in the Hsp70 transfectants than in control (Figure 4C). Taken together, these results indicate that extracellular Hsp70 induces MMP-9 transcription by activating NF- $\mathrm{kB}$ and $\mathrm{AP}-1$.

\section{Discussion}

This study demonstrates that overexpression of Hsp70 in human monocytic cell line U937 induces the expression of MMP-9 gene through the activation of NF-kB and AP-1. Hsp70 cDNA transfectants released Hsp70 protein into culture supernatants, and the protein subsequently bound to the surface of U937 cells. Addition of culture medium, containing the released Hsp70, to U937 cells led to an increase in proMMP-9 secretion and invasiveness in vitro. Immunodepletion of the extracellular Hsp70 abolished its effect on induction of MMP-9 expression. The released Hsp70 activated NF-kB and AP-1, leading to induction of MMP-9 transcription. These results support previous observations that extracellular Hsp70 induces the expression of pro-inflammatory cytokines in macrophages (Asea et al., 2000; Dybdahl et al., 2002).

Hsp70 overexpression led to an increase in the amount of Hsp70 in culture medium. Hsp70 has been known to act not only as an intracellular chaperon, but also as a secretory protein (Chan et al., 1999; Asea et al., 2000; Guzhova et al., 2001; Somersan et al., 2001; Dybdahl et al., 2002; Njemini et al., 2003; Hunter-Lavis et al., 2004; Kimura et al., 2004; Njemini et al., 2004). Secretion of Hsp70 from a variety of cells in response to cellular stress has been widely reported. For example, it has been shown that Hsp70 is present in the sera of normal individuals and its circulating levels are related to the levels of inflammation markers (Chan et al., 1999; Dybdahl et al., 2002; Njemini et al., 2003, 2004). Treatment of macrophages with oxidized low density lipoprotein significantly increased Hsp70 concentration in supernatants, compared with untreated control (Svensson et al., 2005). Analysis of supernatants of transformed cell lines and primary human tumor tissue lysates showed that they contained considerably higher levels of Hsp70 than their normal autologous tissue counterparts (Somersan et al., 2001). The glioma cells were shown to release 5 to $15 \mathrm{pg}$ of Hsp70 per $10^{6}$ cells per day into the culture medium under normal conditions, but the amount increased following heat shock (Guzhova et al., 2001). These results indicate that $\mathrm{Hsp} 70$ can be released into the cultured medium or extracellular space from a variety of cell types in certain circumstances.

Hsp70 in the culture medium or serum may result from cell death-mediated release or its active secretion from cells. Our kinetic analysis of extracellular Hsp70 showed that during $24 \mathrm{~h}$ culture, there was about a 14-fold increase in Hsp70 present in the culture medium, but about a two-fold detectable increase in $\beta$-actin, an intracellular protein control. This result is consistent with previous data, suggesting that a major fraction of Hsp70 is actively released into the cell culture medium (Broquet et al., 2003; Hunter-Lavis et al., 2004; Lancaster and Febbraio, 2005). Two recent studies have provided evidences that Hsp70 can be actively released into the culture medium via specialized membrane microdomains, termed lipid rafts (Broquet et al., 2003; Hunter-Lavis et al., 2004). In addition, exonemes have been shown to play a role in the active secretion of Hsp70 from human peripheral blood mononuclear cells in both basal and heat shockinduced states (Lancaster and Febbraio, 2005).

Purified Hsp70 has been shown to act as a novel cytokine, which causes monocytes to express proinflammatory cytokines such as IL-1, IL-6, and TNF- $\alpha$ (Asea et al., 2000; Esparza et al., 2004). However, other reports suggested that Hsp70-mediated induction of proinflammatory cytokines might be due to contamination by LPS as well as LPS-associated molecules (Gao and Tsan, 2003a, b). In the present study, we treated cells with LPS-free Hsp70 proteins 
expressed in the U937 cells rather than Hsp70 produced in bacterial cells, and then investigated its effect on MMP-9 activity. Addition of culture supernatants containing the secreted Hsp70 increased MMP-9 activity and subsequently migrating ability of cells. Furthermore, immunodepletion of the secreted Hsp70 inhibited the induction of MMP-9 expression, thereby clearly showing that extracellular Hsp70 itself rather than endotoxin contamination activated inflammatory-related genes.

Our present study showed that Hsp70 overexpression induced MMP-9 gene expression by activating $\mathrm{NF}-\mathrm{k} B$ and $\mathrm{AP}-1$. Hsp70 may activate the innate immune system in a manner similar to that of LPS and bacterial lipoproteins. Binding of LPS to TLRs induces activation of the transcription factor $\mathrm{NF}-\kappa \mathrm{B}$ in host cells upon infection (Kirschning et al., 1998). In this study, we showed that the secreted Hsp70 was bound to cell surfaces, although we did not determine whether it was bound to TLRs. Extracellular $\mathrm{Hsp} 70$ might potentiate NF-KB activation, inducing a pro-inflammatory response typical of LPS. Indeed, soluble Hsp70 appears to induce production of proinflammatory cytokines by stimulating the CD14, TLR2 and TLR4 complex signaling pathways (Asea et al., 2002; Vabulas et al., 2002). Interestingly, a recent study demonstrated that heat shock induced the expression of TLR2 and TLR4 prior to that of Hsp70 in monocytes (Zhou et al., 2005). Induction of heat shock response may activate proinflammatory gene expression by up-regulating not only the secretion of extracellular Hsp70 proteins, but also their binding to TLRs.

In summary, we demonstrated that overexpression of Hsp70 led to the release of Hsp70, which was bound to the cell surface of monocytes, and induced the expression of MMP-9 gene through activation of $N F-\kappa B$ and AP-1. These data not only support the previous reports suggesting that the extracellular Hsp70 may activate pro-inflammatory cytokine genes in human monocytes, but also suggest that Hsp70induced MMP-9 activation may play a role in the transmigration of leucocytes into the inflamed tissues. Further studies are required to investigate the functional role of extracellular $\mathrm{Hsp} 70$ that can be induced under pathological conditions.

\section{Acknowledgment}

This work was supported by Vascular System Research Center grant of the Korea Science and Engineering Foundation. We thank Yoon-Kyoung Kim and Si-Eun Kim for their technical help.

\section{References}

Adewoye AH, Klings ES, Farber HW, Palaima E, Bausero MA, McMahon L, Odhiambo A, Surinder S, Yoder M, Steinberg MH, Asea A. Sickle cell vaso-occlusive crisis induces the release of circulating serum heat shock protein-70. Am J Hematol 2005;78:240-2

Asea A, Kraeft SK, Kurt-Jones EA, Stevenson MA, Chen LB, Finberg RW, Koo GC, Calderwood SK. HSP70 stimulates cytokine production through a CD14 dependent pathway, demonstrating its dual roles as a chaperone and cytokine. Nat Med 2000;6:435-42

Asea A, Rehli M, Kabingu E, Boch JA, Bare O, Auron PE, Stevenson MA, Calderwood SK. Novel signal transduction pathway utilized by extracellular HSP70: role of Toll-like receptor (TLR) 2 and TLR4. J Biol Chem 2002;277:15028-34

Bausinger $\mathrm{H}$, Lipsker D, Ziylan U, Manie S, Briand JP, Cazenave JP, Muller S, Haeuw JF, Ravanat C, de la Salle H, Hanau D. Endotoxin-free heat-shock protein 70 fails to induce APC activation. Eur J Immunol 2002;32:3708-13

Broquet AH, Thomas G, Masliah J, Trugnan G, Bachelet M. Expression of the molecular chaperone Hsp70 in detergent-resistant microdomains correlates with its membrane delivery and release. J Biol Chem 2003;278:21601-6

Chan YC, Shukla N, Abdus-Samee M, Berwanger CS, Stanford J, Singh M, Mansfield AO, Stansby G. Antiheat-shock protein $70 \mathrm{kDa}$ antibodies in vascular patients. Eur J Vasc Endovasc Surg 1999;18:381-5

Dybdahl B, Wahba A, Lien E, Flo TH, Waage A, Qureshi N, Sellevold OFM, Espevik T, Sundan A. Inflammatory response after open heart surgery: release of heat-shock protein 70 and signaling through toll-like receptor-4. Circulation 2002;105: 685-90

Dybdahl B, Slordahl SA, Waage A, Kierulf P, Espevik J, Sundan A. Myocardial ischaemia and the inflammatory response: release of heat shock protein 70 after myocardial infarction. Heart 2005;91:299-304

Esparza J, Kruce M, Lee J, Michaud M, Madri JA. MMP-2 null mice exhibit an early onset and severe experimental autoimmune encephalomyelitis due to an increase in MMP-9 expression and activity. FASEB J 2004;18:1682-91

Gao B, Tsan MF. Endotoxin contamination in recombinant human heat shock protein 70 (Hsp70) preparation is responsible for the induction of tumor necrosis factor alpha release by murine macrophages. J Biol Chem 2003a;278:174-9

Gao B, Tsan MF. Recombinant human heat shock protein 60 does not induce the release of tumor necrosis factor alpha from murine macrophages. J Biol Chem 2003b;278:22523-9

Gao B, Tsan MF. Induction of cytokines by heat shock proteins and endotoxin in murine macrophages. Biochem Biophys Res Commun 2004;317:149-54

Gething MJ, Sambrook J. Protein folding in the cell. Nature 1992;355:33-45

Guzhova I, Kislyakova K, Moskaliova O, Fridlanskaya I, Tytell $\mathrm{M}$, Cheetham M, Margulis B. In vitro studies show that Hsp70 can be released by glia and that exogenous Hsp70 can en- 
hance neuronal stress tolerance. Brain Res 2001;214:66-73

Hah N, Lee ST. An absolute role of the PKC-dependent NF-kappaB activation for induction of MMP-9 in hepatocellular carcinoma cells. Biochem Biophys Res Commun 2003;305: 428-43

Hartl FU, Hayer-Hartl M. Molecular chaperones in the cytosol: from nascent chain to folded protein. Science 2002;295: $1852-8$

Hightower LE, Guidon Jr PT. Selective release from cultured mammalian cells of heat-shock (stress) proteins that resemble glia-axon transfer proteins. J Cell Physiol 1989;138:257-66

Hong IK, Kim YM, Jeoung DI, Kim KC, Lee H. Tetraspanin CD9 induces MMP-2 expression by activating p38 MAPK, JNK and c-Jun pathways in human melanoma cells. Exp Mol Med 2005;37:230-9

Hunter-Lavis A, Davies EL, Bacelar MM, Marshall MJ, Andrew SM, Williams JH. Hsp70 release from peripheral blood mononuclear cells. Biochem Biophys Res Commun 2004;324: 511-7

Kimura F, Itoh H, Ambiru S, Shimiz H, Togawa A, Yoshidome $\mathrm{H}$, Ohtsuka M, Shimamura F, Kato A, Nukui Y, Miyazaki M. Circulating heat-shock protein 70 is associated with postoperative infection and organ dysfunction after liver resection. Am J Surg 2004;187:777-84

Kirschning CJ, Wesche H, Merrill AT, Rothe M. Human toll-like receptor 2 confers responsiveness to bacterial lipopolysaccharide. J Exp Med 1998;188:2091-7

Lancaster GI, Febbraio MA. Exosome-dependent trafficking of HSP70: a novel secretory pathway for cellular stress proteins. J Bio Chem 2005;208:23349-55

Lee KJ, Kim HA, Kim PH, Lee H, Ma KR, Park JH, Kim DJ, Hahn JH. Ox-LDL suppresses PMA-induced MMP-9 expression and activity through CD36-mediated activation of PPAR- $\gamma$. Exp Mol Med 2004;36:534-44

Nagase H, Barrett AJ, Woessner JF. Nomenclature and glossary of the matrix metalloproteinase. Matrix Suppl 1992;1: 421-4

Njemini R, Demanet C, Mets T. Inflammatory status as an important determinant of heat shock protein 70 serum concentrations during aging. Biogerontology 2004;5:31-8

Njemini R, Lambert M, Demanet C, Mets T. Elevated serum heat-shock protein 70 levels in patients with acute infection: use of an optimized enzyme-linked immunosorbent assay. Scan J Immunol 2003;58:664-9
Opdenakker G, Van den Steen PE, Dubois B, Nelissen I, Van Coillie E, Masure S, Proost P, Van Damme J. Gelatinase B functions as regulator and effector in leukocyte biology. $J$ Leukoc Biol 2001;61:851-9

Sato H, Kita M, Seiki M. v-Src activates the expression of 92-kDa type IV collagenase gene through the AP-1 site and the GT box homologous to retinoblastoma control elements. A mechanism regulating gene expression independent of that by inflammatory cytokines. J Biol Chem 1993;268:23460-8

Somersan S, Larsson M, Fonteneau JF, Basu S, Srivastav P, Bhardwaj N. Primary tumor tissue lysates are enriched in heat shock proteins and induce the maturation of human dendritic cells. J Immunol 2001;167:4844-52

Svensson PA, Asea A, Englund MCO, Bausero MA, Jernas M, Wiklund O, Ohlsson BG, Carlsson LMS, Carlsson B. Major role of HSP70 as a paracrine inducer of cytokine production in human oxidized LDL treated macrophages. Atherosclerosis $2006 ; 185: 32-8$

Tryggvason K, Huhtala P, Hoyhtya M, Hujanen E, Hurskainen T. 70 K type IV collagenase (gelatinase). Matrix 1992;1(suppl): $45-50$

Tsan MF, Gao B. Cytokine function of heat shock proteins. Am J Physiol Cell Physiol 2004a;286:C739-C744

Tsan MF, Gao B. Heat shock protein and innate immunity. Cell Mol Immunol 2004b;1:274-9

Tsan MF, Gao B. Endogenous ligands of Toll-like receptors. J Leuk Biol 2004c;76:514-9

Vabulas RM, Ahmad-Nejad P, Ghose S, Kirschning CJ, Issels $\mathrm{RD}$, Wagner H. HSP70 as endogenous stimulus of the Toll/interleukin-1 receptor signal pathway. J Biol Chem 2002;277: 15107-12

Wang Y, Gao B, Tsan MF. Induction of cytokines by heat shock proteins and concanavalin $A$ in murine splenocytes. Cytokine 2005;32:149-54

Watanabe H, Nakanishi I, Yamashita K, Hayakawa T, Okada Y. Matrix metalloproteinase-9 (92 kDa gelatinase/type IV collagenase) from U937 monoblastoid cells: correlation with cellular invasion. J Cell Sci 1993;104:991-9

Zhou J, An H, Xu H, Liu S, Cao X. Heat shock up-regulates expression of Toll-like receptor-2 and Toll-like receptor-4 in human monocytes via p38 kinase signal pathway. Immunology 2005;114:522-30 